\title{
CREDIBILITY AND APPLICABILITY OF VIRTUAL REALITY MODELS IN DESIGN AND CONSTRUCTION
}

\author{
Stefan Woksepp ${ }^{1,2}$, Thomas Olofsson ${ }^{1}$ \\ ${ }^{1}$ eBygg - Center for Information Technology in Construction, Dep. of Civil \& Environmental Engineering, Luleå \\ University of Technology, Sweden \\ ${ }^{2}$ NCC Construction Sverige AB, Sweden
}

\begin{abstract}
In this article we present the findings from an extensive case study of the use of Virtual Reality (VR) models in large construction projects. The study includes two parts: The first part presents a quantitative questionnaire designed to investigate how VR models are experienced and assessed by the workforce at a building site. The second part includes a qualitative field survey of how VR models can be applied and accepted by professionals in the design and planning process of a large pelletizing plant. Through mainly studying persons who had little or no experience with advanced IT, we hoped to reveal the attitudes of the average person working at a construction site rather than of an IT expert.
\end{abstract}

In summary, the study shows that the VR models in both projects have been very useful and well accepted by the users. Today's information flow is, from a general point of view, considered to be insufficient and the hypothesis is that using $V R$ models in the construction process have the potential to minimize waste of resources and improve the final result.

KEYWORDS: construction project, design stage, field survey, planning, questionnaire, virtual reality.

\section{INTRODUCTION}

The information handling in construction projects are often based on traditional media, such as drawings, Gantt schedules and written specifications, which only provide a limited information transfer between the stakeholders of the project (Kähkönen 2003). These conditions do not provide a solid foundation for an effective construction process, (e.g. Egan 1998, Koskela et al. 2003 and Kunz et al. 2005). Advances in Information Technology (IT), especially computer graphics and CAD systems have changed the way we work. However, the full potential on project level is yet to be reached (e.g. Woksepp et al. 2006). VR offers a natural medium for the users providing a three-dimensional view that can be manipulated in real-time and used collaboratively to explore and analyze design options and simulations of the construction process, (Bouchlaghem et al. 2005), It is only recently that VR have started to be used in construction projects and there has been little empirical investigation of VR technologies by companies in the construction sector (Whyte 2001). For example, the proper use of VR models in the different phases of a construction project is still not clear (Westerdahl et al. 2006).

\section{RESEARCH AIM AND OBJECTIVES}

The aim of the case studies presented is to explore and provide insight and knowledge of how VR models are apprehended and used by AEC professionals in their everyday work. The two cases included:

- A quantitative questionnaire of how VR models was experienced and assessed by professionals involved in the construction of the large building project, and to what extent to VR could complement the use of traditional 2D CAD drawings. Here, the operational use of VR at the building site was the primary target.

- A qualitative field survey of how VR models was applied and accepted by professionals in the design and planning process of the construction of a large process plant.

Conclusions are drawn from these two cases.

\section{RELATED WORK}

Bouchlaghem et al (2005) studied the applications and benefits of visualization in construction projects covering collaborative working and design in the conceptual design stage, marketing process in the house building sector and modeling of design details in the construction stage. The study concluded that: visualization can improve communication and collaboration amongst designers during conceptual design; in housing development, site layout models could be used as marketing tools or for planning consultations with planners. Westerdahl et al (2006) made a study of how employees of a company of their yet-to-bebuilt workplace apprehended a VR model of the architec- 
tural design. The results indicated that the VR model helped the decision-making process and provided a good representation of the future workplace. Savioja et al (2003) studied the use of VR models in the construction of a new lecture hall in Helsinki. The process started from a basic VR model for presentation of the concept and layout. The model was further detailed until a photorealistic model of the building could be presented and used for detailed studies of the design. The study concluded that VR improved the communication and the project participants were enthusiastic about the possibilities of VR. Messner et al (2006) studied the value of visualizing of design and construction information in the decision process. The use of visualization tools for design tasks was found to improve collaboration and communication between involved stakeholders. Dawood et al (2005) presented a visual planning tool (VIRCON) with the objective of assisting construction planners to make accurate and informed planning decisions with particular emphasis on the allocation of work space. Especially, space planning in combination with visualization was found useful in tests evaluated by professionals.

\section{THE CENTRALHUSET PROJECT - CASE 1}

The first case study is a questionnaire study that aim to investigate how a visualized VR model was experienced and assessed by the workforce in the construction of a large hotel and office block, Centralhuset. The new 34,000 square-meter building at the bus and rail station in Gothenburg was constructed between the spring of 2001 and the autumn of 2003 . Up to 230 people was employed at the site and the construction cost was approximately EUR $50 \mathrm{M}$. The building includes a hotel block, an office block and commercial and restaurant premises. Figure 1 shows three screenshots from the VR model including the steel structure, foundations and piles and a proposal for office space.

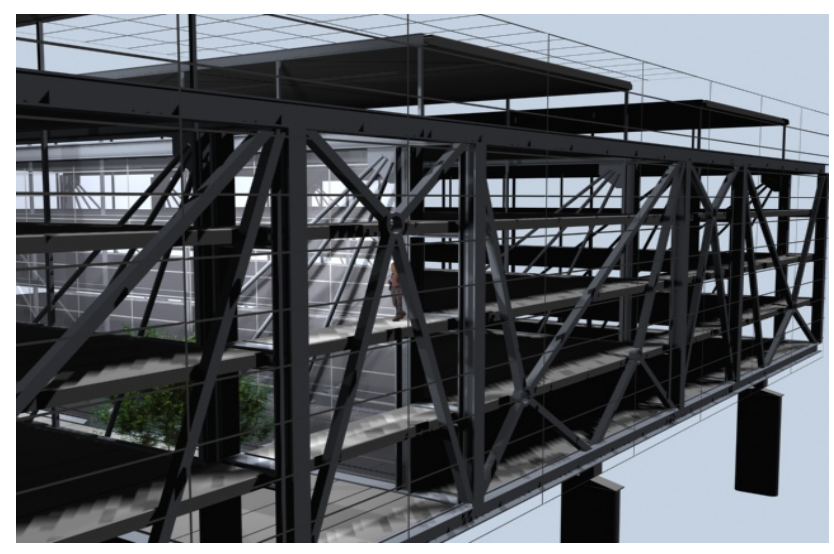

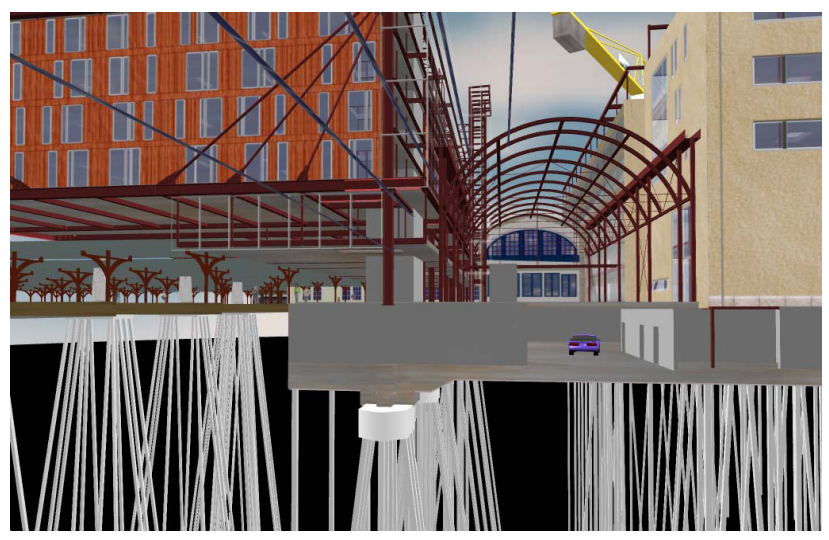

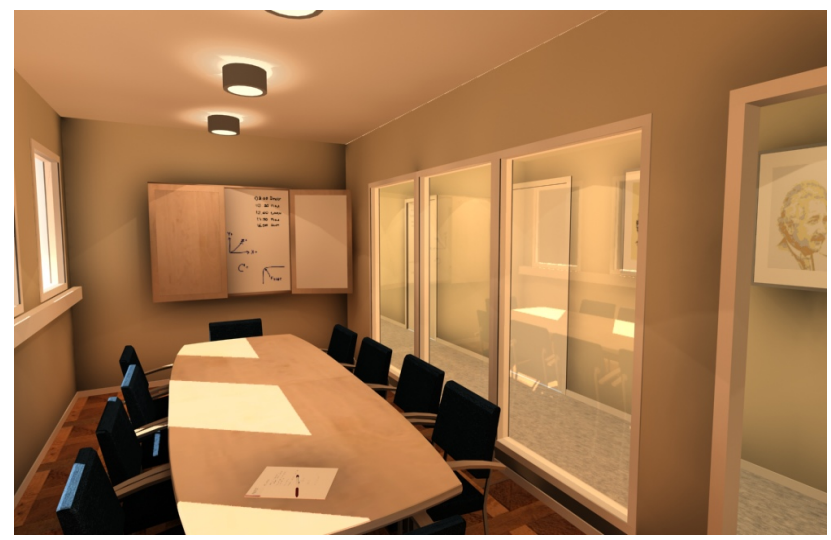

Figure 1. Screenshots from the VR model of Centralhuset.

\subsection{The VR system}

The VR demonstrations can be described as desktop immersive. A common 2-dimensional projector visualized the VR model on a screen. Two PCs and the visualization tool Division MockUp (PTC) were used for the VR visualizations and a Magellan Space mouse was used to navigate in the interactive Virtual Environment. The software and hardware used in the study are commercial and available on the market and was chosen for its functionality, price, flexibility and full compatibility with the most common CAD formats. The investment can be described as reasonable, i.e. suitable not only for large but also for small and medium sized enterprises.

\subsection{The VR model}

The VR models of the Centralhuset were constructed from 2D CAD drawings, 3D CAD models and objects supplied by the architects, designers and other subcontractors. Additional sources detailing the surroundings, such as ortophotos and photos of building exteriors, were purchased from the National Land Survey of Sweden (LMV) or produced using digital cameras. Imported into the VR software, the model could be structured in an assembly manager with hierarchical and parent-child relations (tree-structure). This facilitated breaking down the VR model into modules or "sub-models" depending on application. This also allowed the users to create VR object catalogues and to distribute (via LAN, Internet, CD et cetera) streamlined VR models for different purposes. Additional features and objects, such as textures, ortophotos, the construction crane, site office, rail area, and exist- 
ing rail station, were subsequently added. The VR model of Centralhuset includes the adjacent surroundings, excavations, the cast-in-place basement, piles and pile footings, prefabricated and cast-in-place supporting structure (steel and concrete), pre-fabricated and cast-in-place floors, parts of the façade, rail area (platforms, railway tracks, et cetera), site office, and a moving crane. The exact locations and angles of all 347 cohesion pilings were visualized. The equipment together with the VR model was installed at the building site. During construction, the VR model was maintained and updated with vital information. To facilitate the distribution of information, a local website was set up where the users could present data for downloading. This website also served as a meeting place where images and animations could be downloaded and studied. Approximately 350 working hours was spent to construct the 10,000-object VR model, at a cost of approximately EUR 35,000 This expenditure was financed by the research project and the main contractor, NCC Construction Sverige AB. The benefits from exploiting the VR model - primarily as a tool for planning site activities and incoming and on site logistics - were accrued to the construction project.

\subsection{Research methodology}

A questionnaire consisting of 20/21 questions or statements (21 directed at the building owner representatives) was used to evaluate how the different type of actors perceived and assessed the use of VR in the project. The first three questions pertained to individual characteristics age, profession and computer skills. Then, statements for investigating participants' attitudes towards the use of the VR model and the information flow at the building site were presented. The questionnaire closed with a section containing general statements concerning the use of a VR model in the respondents' own profession. Although leading questions or statements should be avoided in a questionnaire - as they could reflect the position of the researcher - we nevertheless decided that an approach of this sort was best for this study:

1. How will the VR prototype be envisaged, experienced and assessed by the users?

2. To what extent can a VR model complement the use of 2D CAD drawings?

The participants were asked to express agreement or disagreement on a five-point Likert scale: "Strongly agree" (5), "Agree" (4), "Undecided" (3), "Disagree" (2) or "Strongly disagree" (1). The Likert scale was used for all the questions in the questionnaire, with the exception of questions relating to personal characteristics, first contact with VR, information flow and the final questions directed at the building owner representatives. The mean and the standard deviation for the participant group as a whole were calculated for each statement.

\subsection{Participants}

Altogether, 93 people participated in the study. The majority of the people involved in the construction of Centralhuset participated in the study. Tables 1 and 2 show the distributions of occupation and age of the 93 respondents. The occupations were of the following categories (see columns 1-8 in table 1): 1. construction workers; 2. site managers; 3 . constructors; 4 . architects; 5 . handling officers; 6. representatives of the building owner; 7. subcontractors; and 8. "others" - "others" including estimators, economy assistants and external specialists.

Table 1. Participants' occupation.

Occupation

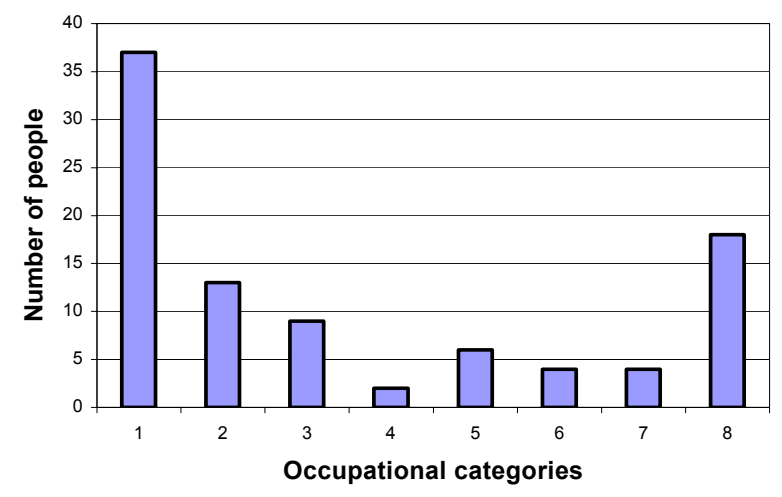

Table 2. Age class distribution.

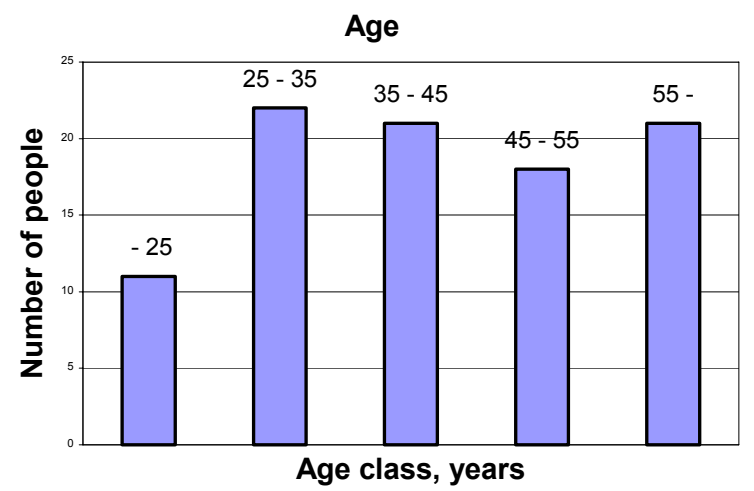

The construction workers were in majority. The age ranged from 20 to 62 years. Differences due to gender could not be investigated, since too few females participated in the study. $57 \%$ of the participants considered themselves to "have good computer skills". For $75 \%$ this was the "first contact with Virtual Reality". The majority of the participants that previously had experience of 3D modeling and/or with VR were designers.

\subsection{Results}

The main goal of the study was to establish whether or not a VR model could be used as a practical and reliable tool to improve communication at the building site. The results from the questionnaire are presented as means and standard deviations in Tables 3, 4 and 5. If not stated otherwise, the response format was a five-point Likert scale $(n=93)$. 
Table 3. Investigating how participants experience use of a VR model.

\begin{tabular}{lc}
\hline Virtual Reality (VR) & Mean value (S.D.) \\
1. First impressions at the VR demonstration & 4.57 (0.54) \\
1a. The VR model provides a better overview of Centrathuset than 2D CAD drawings do. & $4.30(0.69)$ \\
1b. The VR model of Centralhuset has an appearance that inspires confidence in it. & \\
2. Help of navigation in the handling of details & $4.12(0.68)$ \\
2a. Details show up better in VR than in 2D CAD drawings. & $4.16(0.80)$ \\
2b. It is easier for me to explain detais I am involved with professionally with use of a VR & \\
model than with use of 2D CAD drawings. & $4.50(0.70)$ \\
2c. Having the ability to navigate within the VR environnent and thus being able to & \\
scrutinise the model involved from different angles helps me to understand details. & \\
3. Cooperation by use of a virtual environment & $4.01(0.73)$ \\
3a. Cooperation I have with my colleagues within the same occupational group is & $4.20(0.72)$ \\
facilitated by use of a VR model. & \\
3b. Cooperation I have with colleagues from other occupational groups is facilitated by \\
use of a VR model. \\
3c. Details in areas outside my areas of professional competence are easier for \\
me to understand with the aid of a VR model.
\end{tabular}

Table 4. The participants' present and desired future access to information.

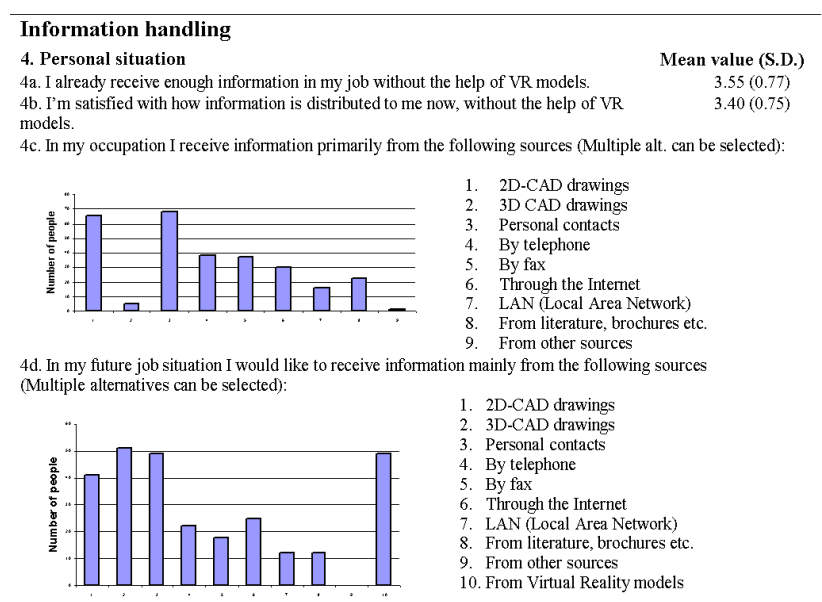

Table 5. Summary of the participants' attitudes toward use of the VR model in work.

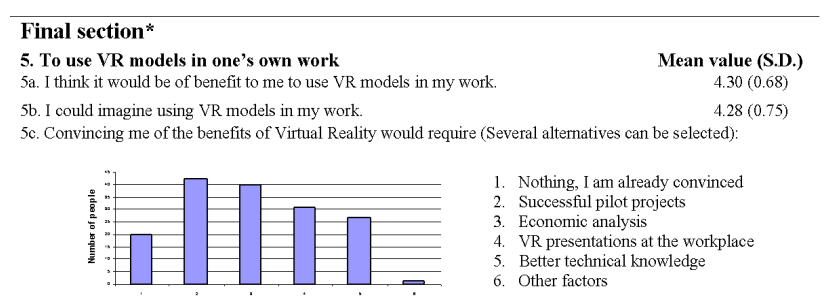

*Two additional questions for the representatives of the building owner are presented last in section 4.5. All participants except the representatives of the building owner answered the first statement in the "Final section".

The result shows that the participants got a good first impression and have confidence in the VR model (1a, 1b). The potential of using the VR model to navigate and to scrutinize and explain details was also considered to be useful $(2 \mathrm{a}, 2 \mathrm{~b}, 2 \mathrm{c})$. The participants also felt that a VR model could facilitate cooperation and understanding within or between occupational groups. However, some participants expressed doubts of being able to create VR models of detailed 3D CAD information in good time for reviewing before performing related site activities. "The time between detailed design and construction is often too short", they said. The result was more ambiguous regarding the use of VR for facilitating information handling (4a and $4 \mathrm{~b}$ ), although $52 \%$ stated that they would like to re- ceive information from VR models in a future job situation (4d). The last part of the questionnaire, "To use VR in one's own work" generated comments such as, "This is great but how do we implement it in our everyday work?" or "Interesting, but can we save any money by using a VR model at the building site? How?" Nevertheless, a majority of the respondents considered VR models to be useful (5a) and could imagine using it in their work (5b). However, some concerns were expressed of the financial benefits and management of VR.

Most of the comments concerned level of detail, costs and possible benefits of VR. The highest potential was believed to be when an unfamiliar task was about to be performed (planning site activities). The rest of the comments related to foreseen problems associated with keeping the VR model up-dated and the need for adaptation to the conditions on the building site. Other comments related to when the major breakthrough for VR in construction was likely to occur. Representatives of the building owner responded to two additional statements:

1.I believe that using VR models can give me a more favorable position in relation to a client.

2. I believe that by using VR, I can reduce the costs of errors sufficiently to cover the costs of the modeling work.

The participants strongly agreed to the first of these two statements $(\mathrm{M}=4.5)$. The second statement received a slightly positive response $(M=3.25)$. Since only four building owner representatives participated, the response is only indicative. A much larger number of participants are needed to ensure reliable responses. However, the estimated cost of the VR model in the Centralhuset project was approximately $2 \%$ and according to Josephson (1990) the errors generated at the site is estimated to be $10 \%$ of the total construction cost.

\section{THE MK3 PROJECT - CASE 2}

The second case concerned how VR models have been applied and accepted by the client and design and planning teams in the construction of a large palletizing plant, the MK3 project. Due to increased demand for upgraded iron ore products for steel making, the Swedish stateowned mining company LKAB has recently increased their capacity by finishing the building of a new pelletizing plant (MK3) in Malmberget, northern Sweden. A workforce up to 250 people was employed by the constructors at the building site, while some 150 consultants and engineers were engaged in the design phase. The total expenditure was approximately EUR $280 \mathrm{M}$. Since time to market is a crucial factor for LKAB, the contractual agreements for co-operation in the project support collaborative working methods such as concurrent engineering, open information flow and introduction of innovations in the design process. The complexity of the project, the number of actors involved and the desire to involve the client and the end-users, such as industrial workers responsible for the plant operations, in the design work makes VR an excellent enriched source of communications. Figure 2 shows three screenshots from the VR models including an overview of the plant, a typical colli- 
sion detected between different teams design (cable ladder and pipes) and a part of the machinery section representing a design review from the aspect of maintenance.
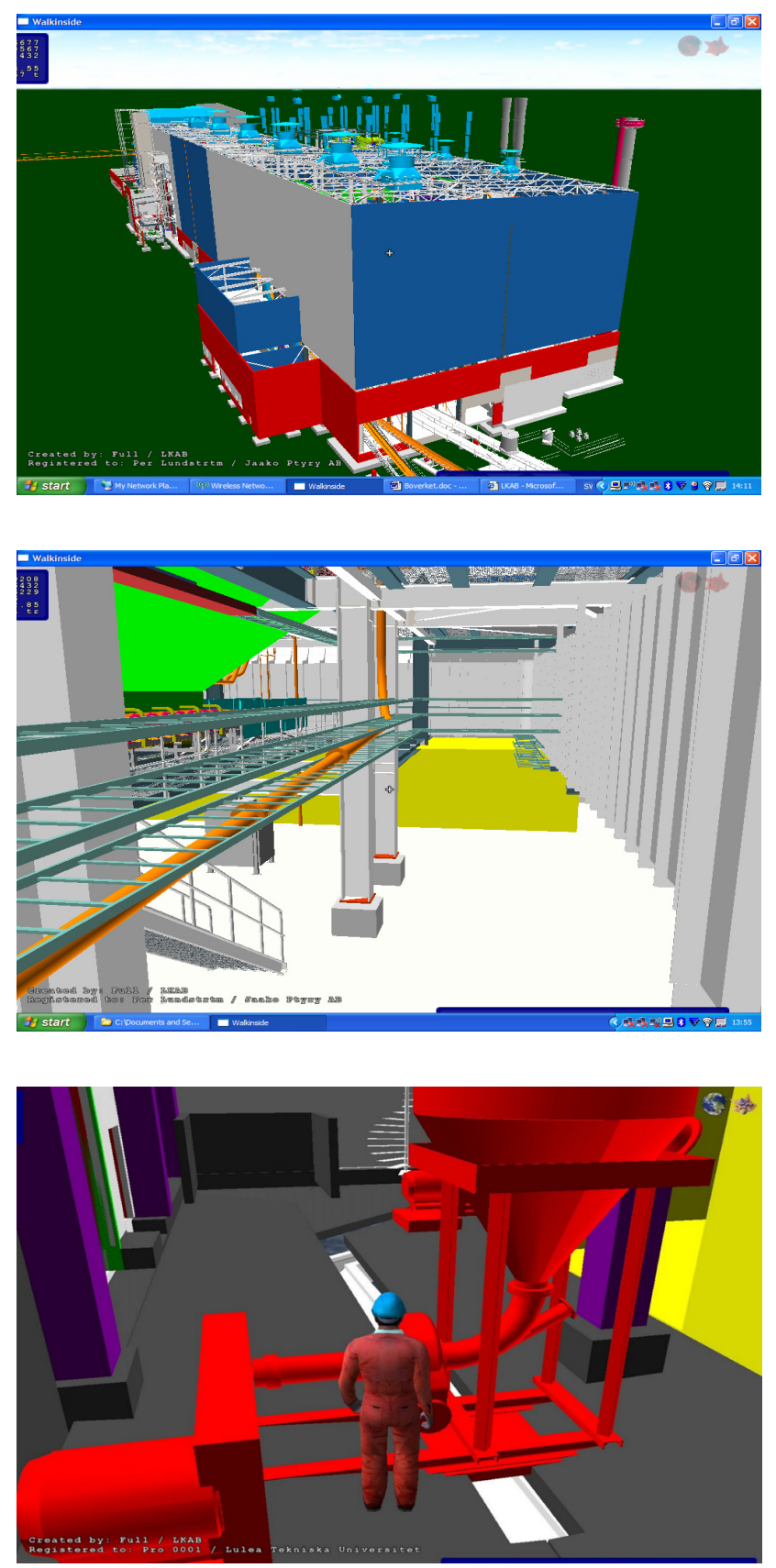

Figure 2. Screenshots from the VR models of the MK3 project.

The purpose of using concurrent engineering in the project was to shorten the lead time. It was decided early in the project that most of the design should be in $3 \mathrm{D}$ and that the different 3D designs should be assembled in digital mock-ups (integrated VR models) for communication and coordination purposes. Design engineers with experience of 3D modelling were recruited to the project and the different design teams selected the 3D CAD tools of their choice. The selection of CAD tools was based on peoples experience not on technical demands!

The design of the plant in the MK3 project was affected by the following parameters:

1. The design of the manufacturing process.
2. Process layout - maintenance, logistics, working environment.

3. The construction of the plant.

The client was responsible for the overall design process while the different design teams were responsible for the design of the subsystems in the plant, i.e. process equipment, building structure, installations, et cetera, and for providing correct and updated input data to the VR models. A VR consultant working for the client managed all the VR data and provided updated VR models accessible for everyone involved in the design process. The different design team exported updated 3D models to a FTP server every two weeks. Various VR models was produced and used in design reviews for different purposes, e.g. design coordination, work environment, clash detection, and planning. Updated VR models were available on the FTP server to the design teams throughout the design phase.

\subsection{The VR system and VR models}

The VR system used in the MK3 project is a low-cost approach that consists of commercial software, PC computers and servers. The visualization tool Walkinside ${ }^{\mathrm{TM}}$, which was selected as VR platform in the project, can import most of the major CAD formats. All presentations of the VR models were interactive and done with computer monitors or 2D-projectors. Most of the information that makes up the VR models of the plant originates from 3D CAD models developed by different design teams. The only exception in the project is the electrical installations that were modeled only in 2D. However, the cabling was later remodeled as 3D CAD objects to show the location of the cable ladders in the plant. The different design teams responsible for the development of steel, concrete, machinery, ventilation, et cetera; extract chosen parts of the $3 \mathrm{D}$ models to be included in the VR models. The design was carried out using a number of 3D CAD applications such as: Solidworks, Tekla Structures, AutoCAD, Microstation (where most of the mapping of material and textures was done) and Intergraph's PDS system. Apart from the use in creation of VR models, most 2D CAD shop drawings were directly generated from the 3D models. The VR consultant converts the uploaded 3D models into VR format and produces different VR models for different purposes, e.g. design reviews, site planning, production, mounting, working environment for safety and maintenance. The VR models were also used for ocular clash detection (automatic clash detection is being carried out in the 3D CAD software by the design teams themselves), distance measuring, user positioning (XYZ coordinates or on an overview, updated in real-time), turning on/off objects layers, gravity, impenetrable objects, the use of avatars for simulation of workforce and trucks, et cetera. The total amount of information describing the VR models of the pelletizing plant is extensive, and includes the construction (prefabricated and cast in place concrete, and the steel structure), the installations (machinery, HVAC, electrical installations) and its surroundings. All expenditures from creating, using and handling the VR models were financed by the client. 


\subsection{Research methodology}

A qualitative research methodology was used. The study is based on field investigations and informal interviews with 12 respondents involved in the design and planning of the construction project.

\subsection{Procedure and participants}

The interviews were conducted on a one-to-one basis in conjunction to the participants' everyday work. This informal method helped us to map out the working process as well as to obtain a deeper knowledge of the experience of using VR in a systematic way throughout the design and construction process. The 12 interviewees, all men, represented the client and a number of subcontractors with responsibilities within project management and planning, design coordination, business management and development (representing the client), technical engineering and VR modeling. All but one, the VR consultant, had several years of experience from similar construction projects. However, the VR consultant was the only one that had some experience of working with VR models. Everyone uses computers frequently and agreed that the amount of information in construction projects is probably enough but needed to be more structured and easier to communicate to the different stakeholders in the project.

\subsection{Results}

The following section summarizes the main findings on the use and benefits of VR from the field study and interviews with the 12 respondents.

A number of VR models were produced throughout the project in order to support the design and planning process. These VR models were fully accepted and considered useful. According to the interviewees, the VR models provided well-structured and easy-to-understand design information throughout the project in a way that is not possible using traditional documents and 2D CAD drawings. The users could analyze the design both from a perspicuous as well as detailed perspective by navigating freely in the VR models, which made it easier to explain and discuss different design solutions with a larger group of professionals with different knowledge and experience.

The VR models were extensively used in the reviews meetings that occurred every two weeks. Here, design solutions were examined from the different perspectives and requirements on function, work environment and maintenance. Clashes between the different design disciplines was also discussed and resolved. The use of VR made the review work much easier and minimized the risk for misinterpretations. This implies that more valuable time could be spent on finding solutions and opportunities. However, one of the greatest advantages in design reviewing as well as in the individual design work was the increased understanding for the overall design. The design teams could, interactively, in a virtual environment, explore different alternatives by predicting, understanding and evaluating the impact on the project as a whole in order to come up with the best solutions for the client. Besides making it easier to make crucial decisions; the VR models have also involved the client in the every- day design work. The use of VR enabled the client to collect opinions from a wider audience, such as the plant operating and maintenance staff. There are several examples in the MK3 project where the VR models have been used to facilitate the client's decision-making in the design process. For example, due of the tight time schedule, the client and the different design teams needed to take quick internal decisions often without consulting the other design teams on a regular design review meeting. The VR models have helped them to better understand the multidisciplinary consequences of a decision. From the client's perspective, the impact of the decision on the manufacturing processes has the highest priority. All other decisions regarding for example construction, $\mathrm{HVAC}$, et cetera, are of subordinate significance. Therefore, when the client had chosen the plant process and the machinery to produce the required capacity, the spatial needs could be defined. These needs were described to the construction design teams using a VR model of the plant process design. The design teams could then begin to plan the layout of the construction and select technical solutions to be discussed, followed up and evaluated in the succeeding design review meetings.

The interviewees concluded that one of the major benefits in the design was the increased level of understanding; especially within areas outside the scope of their own profession, or to quote one of the design managers: "I was skeptical at first but when I realized that by studying one VR model instead of spending time searching through piles of paper drawings could save me a lot of valuable time thus I could focus on what is important". To illustrate his point, he mentioned how much easier it was to design the concrete foundations of the machinery when you get a clear picture from the VR model of how the mounting frames were designed. Using VR models was also considered especially valuable for: providing data to the clients' investment-decision; in the conceptual design of the plant layout; in the detailed design phase and for speeding up the CE-marking of the plant.

A number of VR models were also produced that showed the general phases of the project during construction in order to support the scheduling process. These VR models, which we define as phase models, was accepted and considered useful by the planners. However, it was noted by the planners that the phase models are limited in the sense that they are only approximate representations of a certain state in the construction process, without a direct link to the project schedule. The following examples illustrate the use of VR in the planning of the work:

- The design models are complex as they involve many different disciplines and complex geometries. For example, almost all conveyor belts in the bailing section are sloping away in different directions, often crossing and connecting to parts of the plant that are designed by several other suppliers and designers. VR models could certify constructability and order of assembly. Moreover, VR models have been used in advance to identify critical areas or parts of the plant and have used that information in order to speed up the CEmarking process.

- The construction space is limited, e.g. the work often involves about many different suppliers and contractors at the same time, in the same area. For example, 
assuring that the pipe-installation will not be clustered together in cramped spaces without space for maintenance VR models was used to plan and coordinate the site activities and assure future access.

- Construction time is limited and requires from all involved contractors and suppliers to work with several crews at the same time. Using VR models have facilitated a concurrent approach and helped reducing lead time (from investment decision to start of production) to two years.

- VR models were used to support planning and decision-making of prefabrication. For example, to speed up the production it was decided that larger parts of the belt conveyor system could be assembled off-site after it was checked in the VR model that these preassembled belt conveyor parts could safely be lifted in the plant.

According to the planners, the biggest value from using VR models was obtained from including the setting-out grid (created as "VR solids") in the VR models. The setting-out grid provided the planning teams reference positions from where distances to the construction parts could be measured. This created a common frame of reference and a better spatial understanding. The VR models also facilitated the structuring and handling of the massive amount of information in the planning process. This took some of the work load off the planners.

\section{DISCUSSIONS}

\subsection{The Centralhuset case study}

The aim of the questionnaire study was to investigate the way work force at a large building site experienced and assessed the VR model as well as the intended use for information purposes. The VR model focused primarily on the supporting structure, the foundations and the prefabricated floor components of the building. We expected that some of the occupational groups could have more use for the model than other groups. Therefore, we endeavored to perfect the original version of the VR model to make it as suitable as possible for all the occupational groups involved.

In the questionnaire, three objective personal characteristics of the participants; age, occupation and computer skills, were determined. Only some relationships between these characteristics and the views or attitudes that the participants expressed in their responses could be found; e.g. younger respondents with higher computer skills were slightly more positive to VR and all architects liked the idea to communicate their work using VR models. Although the construction workers were the group whose computer skills were most limited, they were particularly positive in their assessment of the advantages of using VR in the construction process. The fact that they receive information largely from 2D CAD drawings and personal communication may well have contributed to the positive attitude to new and richer forms of communication media. Although we did not perform any significance tests, the reasonably high mean values combined with low standard deviations obtained for most of the test items relating to the participants' attitudes and assessments, indicates a high degree of consensus. This gives a strong indication of the conclusions drawn.

\subsection{The MK3 case study}

According to the interviewees, the use of VR facilitated the concurrent design process; especially in the design coordination process, the design review process and the capturing of client requirements on the final design, and to some extend the planning process. By comparison to the traditionally-used 2D and document-based working methods both designers and planners states that they have obtained a higher degree of spatial understanding and a better understanding of how and when the construction is going to be built. As a result, they have been able to evaluate different solutions and better understand the future consequences of a decision. A rough estimate based on previous experience from a similar project using $2 \mathrm{D}$ drawings by the design coordinator showed that the cost of using VR is much less compared with the savings in design coordination alone once the design is made in 3D. The staff devoted to design coordination was halved (from 15 to 7 designers) compared to the 2D design project. Still, the quality of the design coordination was deemed to be higher in the MK3 project.

The VR models were accepted and considered reliable largely because they directly origin from the different 3D CAD models. However, although the planners considered the VR models to be reliable and also well-structured most of the planning work was done using traditional methods. The two main reasons for this are believed to be that the traditional way of working is still firmly established and that the "right" VR models often were inaccessible when much of the planning work was conducted. There was simply not enough time to produce and present production adapted VR models to the planning team.

Neither realistic VR models (lighting, texture, et cetera) nor the experience of presence was considered to be essential for designing and planning. Computer monitors and projectors (2D) were believed to be sufficient for the VR presentations. According to the client most value has been derived in the use of VR as a decision support in the conceptual design of the plant layout and in detecting collisions in the detailed design phase.

\section{CONCLUSIONS}

Focusing on two case studies - two construction projects - made it possible to go into depth when investigating the use of VR models in large construction projects. However, it should be noted that conclusions drawn should be interpreted in regard to this limited scope.

The results of study 1 indicate that there is a need to improve the information flow at building sites. The usefulness of technical aids, such as VR, appears to be obvious. Indications that can inhibit integration of VR into the building process were also found in limited technical knowledge and financial considerations. The present procedure of distributing information by means of 2D CAD drawings is ineffective. Moreover, designing in 2D rather than directly in $3 \mathrm{D}$ considerably increases the cost of pro- 
ducing a VR model. Additional comments also revealed that it is important to inspire and give confidence in new aids, such as VR models. Otherwise, there is always a risk for a low utilization ratio.

The results of the study 2 indicate that client and the great majority of the designers and planners accepted and were positive about using VR models as a tool for improving information handling in the MK3 project. The usefulness in both the design and planning process was acknowledged. In the beginning of the project both fascination and skepticism over the VR technology was noted which was thought to influence the acceptance and credibility of the VR models. However, these symptoms quickly vanished when the use of VR models become a natural part in the daily work. Also, several respondents argued that the use of VR will probably increase in future project and that more built-in intelligence in the VR model will extend its use in designing, planning and process simulation.

\section{REFERENCES}

Bouchlaghem D., Shang H., Whyte J. and Ganah A. (2005) Visualisation in architecture, engineering and construction (AEC), International Journal of Automation in Construction, Vol. 14, pg. 287-295.

Dawood N., Scott D., Sriprasert E. and Mallasi Z. (2005) The virtual construction site (VIRCON) tools: An industrial evaluation, ITcon Vol. 10, pg. 43-54, http://www.itcon.org/2005/5.

Egan J. (1998) Rethinking Construction: The report of the Construction Task Force to the Deputy Prime Minister, John
Prescott, on the scope for improving the quality and efficiency of UK construction, London, Department of the Environment, Transport and the Regions, UK.

Koskela L., Ballard G. and Howell G. (2003) Achieving change in construction, Proceedings of the International Group of Lean Construction 11th Annual Conference (IGLC-11), Virginia Tech, USA, 22-24 July.

Kunz J. and Fischer M. (2005) Virtual Design and Construction: Themes, Case Studies and Implementation Suggestions, CIFE Working Paper \#097, Center For Integrated Facility Engineering, Stanford University, USA.

Kähkönen K. (2003) Editorial: virtual reality technology in architecture and construction, ITcon Vol. 8, Special Issue Virtual Reality Technology in Architecture and Construction, pg. 101-103, http://www.itcon.org/2003/8.

Messner J. I., Riley D. R. and Moeck M. (2006) Virtual facility prototyping for sustainable project delivery, ITcon Vol. 11, pg. 723-738, http://www.itcon.org/2006/51.

Savioja L., Mantere M., Olli I., Äyräväinen S., Gröhn M. and Iso-aho J. (2003) Utilizing virtual environments in constr. projects, ITcon Vol. 8, pg. 85-99, http://www.itcon.org/2003/7.

Westerdahl B., Sunesson K., Wernemyr C., Roupé M., Johansson M. and Allwood C. M. (2006) Users' evaluation of a virtual reality architectural model compared with the experience of the completed building, International Journal of Automation in Construction Vol. 15, pg. 150-165.

Whyte J. and Bouchlaghem D. (2001) IT innovation within the construction organization, Proceedings of the International Conference on Construction Information Technology, Mpumalanga, South Africa, pg. 32/1-32/12.

Woksepp S and Olofsson T. (2006) Using Virtual Reality in a large-scale industry project, ITcon Vol. 11, pg. 627-640, http://www.itcon.org/2006/43. 